\title{
Respite for NASA's troubled data system
}

[WASHINGTON] The US National Aeronautics and Space Administration (NASA) was this week optimistic that its troubled computer system for handling vast amounts of data from a planned constellation of Earthobservation satellites will be up and running for the scheduled launch of the first major satellite, AM1, next June. The system has just come through a critical test.

Past problems with the system, which will underpin the world's largest Earth-observation programme - the US Earth Observing System (EOS) — had left it 18 months behind schedule. The \$6-billion EOS is intended to provide information on the atmosphere, oceans and solid Earth for at least a decade.

The data-handling system — EOS Data and Information System (EOSDIS) - is vitally important, because, once operational, the satellites will generate about 1 terabyte of data daily. In six months they will produce the equivalent of NASA's entire 25-year archive of remote-sensing data. The EOSDIS 'core system', which will process raw science data from the EOS satellites, failed in tests last January. This, combined with management and budgetary problems, resulted in the delay to the project. Even now there is "very little, if any, slack" in the development schedule, says Rick Obenschain, who manages the EOSDIS at the space agency's Goddard Space Flight Center in Maryland.

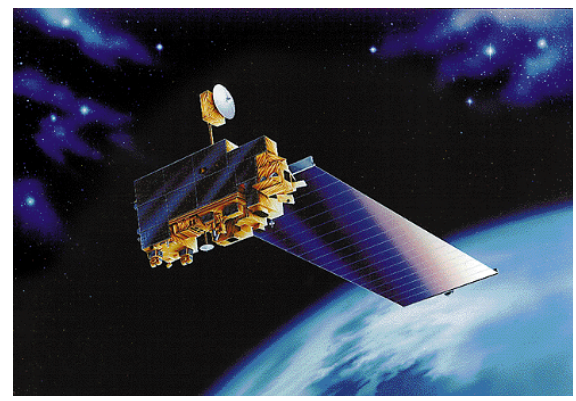

EOS AM-1: project's data system now back on track?

The recent tests were designed by an outside review group established by NASA and chaired by Sara Graves, a computer scientist at the University of Alabama in Huntsville. Checks included verifying that the system could ingest raw data from Landsat and other satellites, for example, and that scientists could log on and retrieve data. The system accomplished all 42 of the tasks it was given.

Nevertheless, many scientists working on EOS are still pressing for EOSDIS to be replaced by a decentralized system giving greater control of data processing to the teams that designed the instruments. Such an approach has been endorsed by NASA advisory groups (see Nature 386, 203; 1997). But there seems to be a growing acceptance that NASA has gone so far down the EOSDIS road that it must try to get the most out of its invest-
ment.EOSDIS, including archive centres, will cost $\$ 1.8$ billion over ten years. The core system alone - being developed by the Hughes Information Technology Company of Landover, Maryland - will cost $\$ 680$ million.

Obenschain also warns that any alternative system could be at least as expensive as EOSDIS. NASA has agreed, on the advice of two outside advisory groups, to run the system at a quarter-capacity in the first year of operation. This will save money and make it easier to resolve teething problems. But it means that scientists will have to compete for reduced resources. A committee chaired by Eric Barron, an EOS interdisciplinary investigator from Pennsylvania State University, has the task of recommending which projects should be given priority during this period.

Any decision to change EOSDIS radically will probably have a political component. Despite its problems with the core system, Hughes has a home-state ally in Senator Barbara Mikulski (Democrat, Maryland), who is an influential member of the Senate appropriations committee that controls NASA's budget. Indeed, the committee advised NASA this summer, in a report accompanying the agency's spending bill, that it expects the Hughes contract to continue "in its current structure" provided the company meets set targets for delivering successive versions of the core system software.

Tony Reichhardt

\section{Earth scientists count the cost of loss of Lewis demo satellite}

[WASHINGTON] Hope is fading that

US ground controllers will be able to regain control of the $\$ 71$-million Lewis demonstration satellite before it re-enters the Earth's atmosphere around midSeptember.

The satellite, which is testing the feasibility of hyperspectral imagery of Earth as well as advances in spacecraft design, went into a spin on 26 August, shortly after launch, and radio contact was lost (see Nature $\mathbf{3 8 9}$, 10; 1997). Project managers at the California-based company TRW, Inc., which built and operated Lewis under contract to NASA, had hoped that the tumbling satellite's solar panels might absorb enough sunlight to recharge onboard batteries and bring the craft back to life. But as Nature went to press, this had not happened. NASA officials describe the chances of recovering the satellite as slim.
The high-profile project was also an experiment in mission management, with the private contractor TRW operating the craft with minimal involvement from NASA. To save money, TRW employed a lean management team and minimal tracking facilities, and some observers argue that this may have contributed to the problem.

A NASA source alleges that the Lewis control room in Chantilly, Virginia, was left unattended for several hours during the period that the satellite began to spin. Officials at NASA and TRW declined to confirm or deny this. One NASA official says the accident resulted from "a series of very low probability events happening at the wrong time". The official also argues that the loss cannot be blamed on either the private contractor or NASA's recent policy of "better, cheaper, faster" missions. "What went wrong on this project could have gone wrong on any project," he said. The Lewis mission has been strongly supported by Dan Goldin, the NASA administrator, who is keen to see greater private sector involvement in space activities.

Although TRW is managing the recovery effort, NASA has brought its own expensive resources to bear. The large antennas of the Deep Space Network and orbiting Tracking and Data Relay Satellites were enlisted last week to try to force the spacecraft to point its solar arrays at the Sun. But because the spacecraft is spinning, its radio receiver is not pointed in any one direction, making it difficult to send commands.

The loss of the Lewis spacecraft would be a blow to Earth scientists, who have been eagerly awaiting test results from two advanced hyperspectral imagers; these have been flown on aircraft but never on a civilian satellite. Hyperspectral imagery is considered to be the next major advance in satellite remote sensing, because it allows imaging using hundreds of spectral bands, whereas conventional Earth observation satellites use only a dozen or so bands.

The Lewis craft was intended to test whether hyperspectral imagery would be able to distinguish between different types of trees in a forest, and to assess their health on the basis of leaf chemistry. The imagery technique also has potential applications in mineral mapping, agriculture and planetary exploration; indeed, one of Lewis's two imagers was originally developed to fly on a NASA Pluto mission, which has since been put on hold.

Tony Reichhardt 